\title{
Design and application of marine boiler control system based on PLC and touch screen
}

\author{
Baocheng $\mathrm{Lu}^{1, \mathrm{a}}$, Jing $\mathrm{Li}^{2, \mathrm{~b}}$ \\ ${ }^{12}$ Binzhou Polytechnic, No.919, Huanghe 12 Road,Binzhou,Shandong Province, China \\ a176816963@qq.com, b358208755@qq.com
}

Keywords: PLC; touch screen;marine boiler control system

Abstract. PLC technology and touch screen technology is combined together in order to design a marine boiler control system which realizes the remote visual control.Using PLC and EM235 module realizes analog signal control in order and make the control process stable and feasible. The automatic control module PLC is explained in detail,along with analog signal transmission module EM235 and human-computer interface module MCGS, the hardware architecture and software architecture of the whole system. Therefore, the experimental results show the feasibility and effectiveness of the system . this system prove that it can improve control function of boiler.

\section{Introduction}

Traditional marine boiler uses relay-contactor control system. The control process requires a lot of mechanical contact; the system wiring is complex; fault diagnosis and elimination are difficult; the reliability is not high.Once a fault occurs,it will affect the use of marine power plant and delay shipping, resulting in economic losses.Although after a series of optimization by manufacturers, the problem of low reliability is still difficult to solve.

PLC has many advantages which the traditional relay lacks, including fast response,convenient communication, reliability,redundancy, security, and editing characteristics. This design uses the PLC to control the boiler water level, steam pressure,combustion, water quality,excessive air discharge and alarm system, which can effectively improve the reliability of the control system of the boiler and ensure the normal operation of marine power plant.

\section{Design Principle}

The The core of boiler automatic control system is PLC. All the data of the sensor are sent into the PLC input channel.PLC control boiler water level, steam pressure, water quality, combustion and alarm according to the predetermined procedures, realizing automatic start, stop and switch of water pump and oil pump and maintaining the normal operation of the boiler. When the boiler parameters exceed the set value,the system can automatically open sound and light alarm. When the steam pressure is high but not automatically stop the boiler,the steam pressure high alarm sounds firstly, then the steam pressure extra high alarm forces shutdown, and boiler steam excessive release device is started automatically to release stream to the condenser and meanwhile makes continuous alarms. At the same time in order to ensure safety, the system also includes emergency stop button to ensure that at any time a key stop can work.

\section{Hardware composition}

Boiler automatic control system includes PLC control module,boiler water level control module,steam pressure control module,combustion control module,water quality monitoring module,steam excess monitoring and release module,centralized alarm module and visual operation module. 


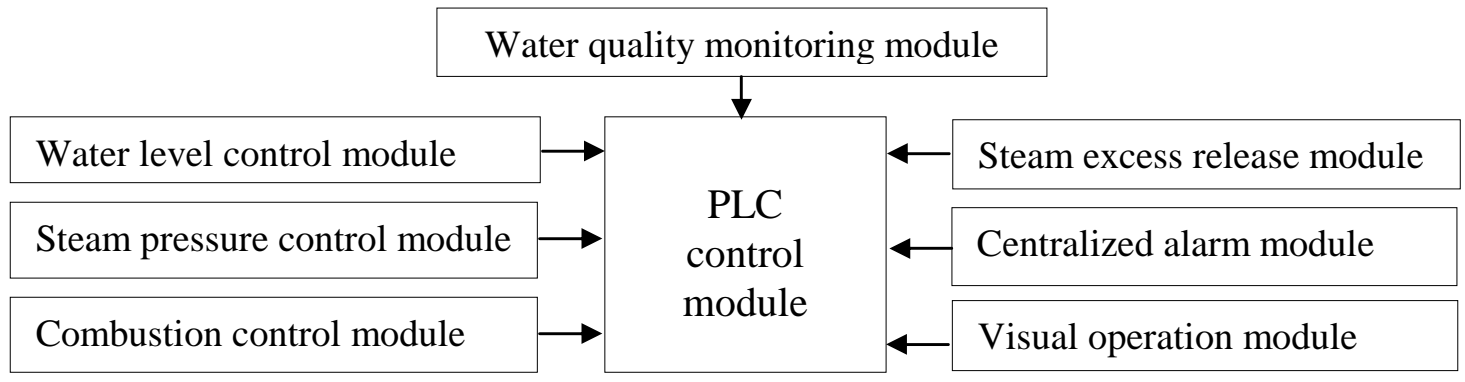

Figure 1 Automatic control system diagram

\section{PLC control module}

According to the system design, PLC control module is mainly composed of SIEMENS S7-200PLC .According to the needs of I/O points, we choose the CPU226, At the same time the PLC adds two EM235 extension modules. It adds 1 EM232 extension module. PLC communicates with other peripherals using module EM277.We chose EM277 to connect S7-200 to the PROFIBUS-DP network.

\section{Boiler water level control module}

The boiler water level control module is composed of the liquid level transmitter, the boiler water level display instrument, feed pump control box and so on.It can realize the boiler automatic feeding water pump, switch, water level real-time display and liquid level abnormal alarm. The model of the liquid level transmitter is CLT-ISOL-24, which is responsible for the detection of water level and transmission of level signals. Boiler water level display instrument selects WL-T803-01-23-HLP model, installed in the control desk of the engine control room.

\section{Boiler steam pressure control module}

The boiler steam pressure control module is composed of steam pressure transmitter and so on. Steam pressure transmitter uses MF1567-3CA00-1AA1 model,The steam pressure signal is converted to $4 \sim 20 \mathrm{~mA}$ current signal to PLC.PLC controls the size of the burner air duct opening. At the same time, the burner start or stop signal is issued to the combustion program controller, and the boiler steam pressure value is displayed When the steam pressure is high, the alarm sounds.

\section{Boiler combustion control module}

The boiler combustion control module is composed of an air door regulator, an oil pump variable frequency motor and an oil pump speed sensor. PLC monitors the boiler steam pressure. When the steam pressure is lower than the low pressure setpoint $0.45 \mathrm{Mpa}$ it sends boiler lighting signal. When the pressure reaches the high pressure set $0.7 \mathrm{Mpa}$ value, it sends out the stop signal, completely automatically controlling the boiler operation.In addition, PLC controls the size of the burner air door opening according to the steam pressure signal in the $4 \sim 20$ ma.The speed of the oil pump and the fuel injection quantity are controlled by the frequency converter, so the size of the flame can be calculated according to the steam pressure of the boiler .Oil pump speed, whether the flame is normal and so on issue abnormal alarm or shutdown command through the corresponding monitoring device.

\section{Boiler water quality monitoring module}

Boiler water quality monitoring module comprises a conductive electrode, the water content 15PPM alarm device, the conductivity of conductive electrodes to detect the boiler water, boiler water 
salinity monitor to transmit the signal to the resolution. When the salinity is too high, alarm signal is sent to PLC alarm system.

\section{Centralized alarm module}

All alarm and indication signals controlled by PLC get into the PLC computer system. After being dealt with by CPU, alarm and lighting display signals are sent to output channel for alarm and light show, and meanwhile sent to the engine room itinerant detection system.

\section{Visual operation module}

Use the touch screen to operate the whole process, display the input and output, check the alarm and adjust the parameters. Touch screen selection model: MCGS TPC7062Ti Cortex-A8 CPU, Kunlun Tongtai, 7 inch four wire resistive touch screen display with embedded integration, with powerful display and data processing functions.

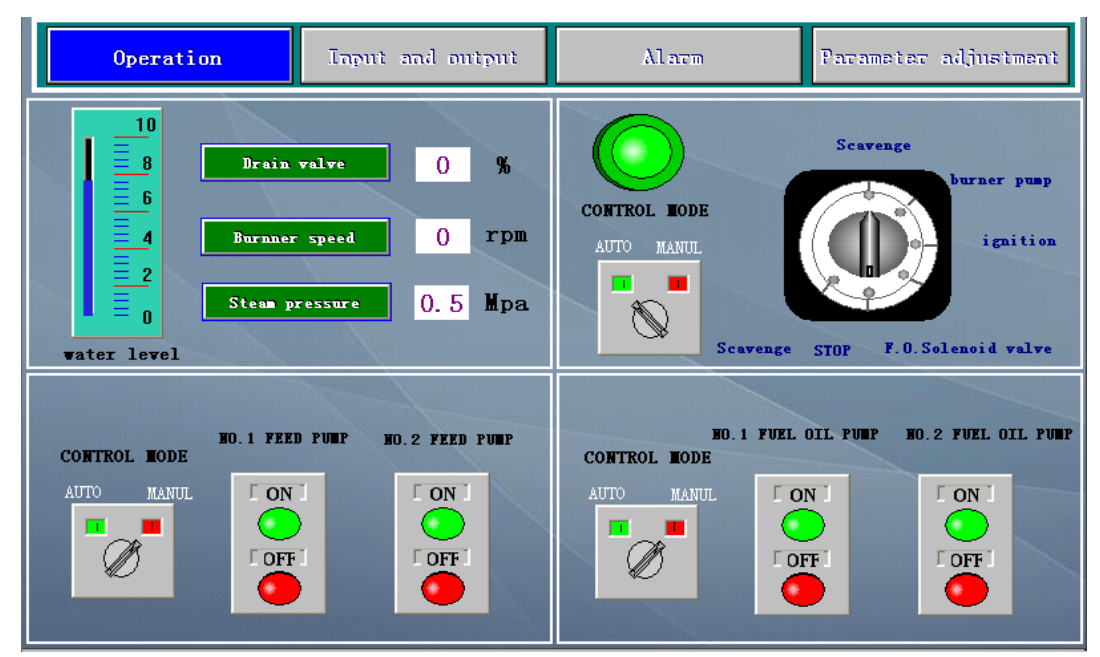

Figure 2 Automatic control system interface

\section{Boiler steam excess release module}

Boiler steam excess release module consist of the I/P signal conversion device, steam release device, etc. When the PLC detects that the stream pressure reaches $0.7 \mathrm{Mpa}$, the output signal of the steam discharge device is transferred to the I/P analog conversion device, and the excess steam is released by the STEAM DUMP VALVE, when the steam pressure is too high, the alarm is sent out.

\section{Software design}

\section{System communication}

This system mainly uses STEP7-Micro/WIN32 as programming software, modular programming of the system implementation process, S7-200 CPU uses EM277 PROFIBUS-DP module to connect the PROFIBUS-DP network and uses S7-200 CPU EM277 to read / write data. 


\section{PLC I/O resource allocation}

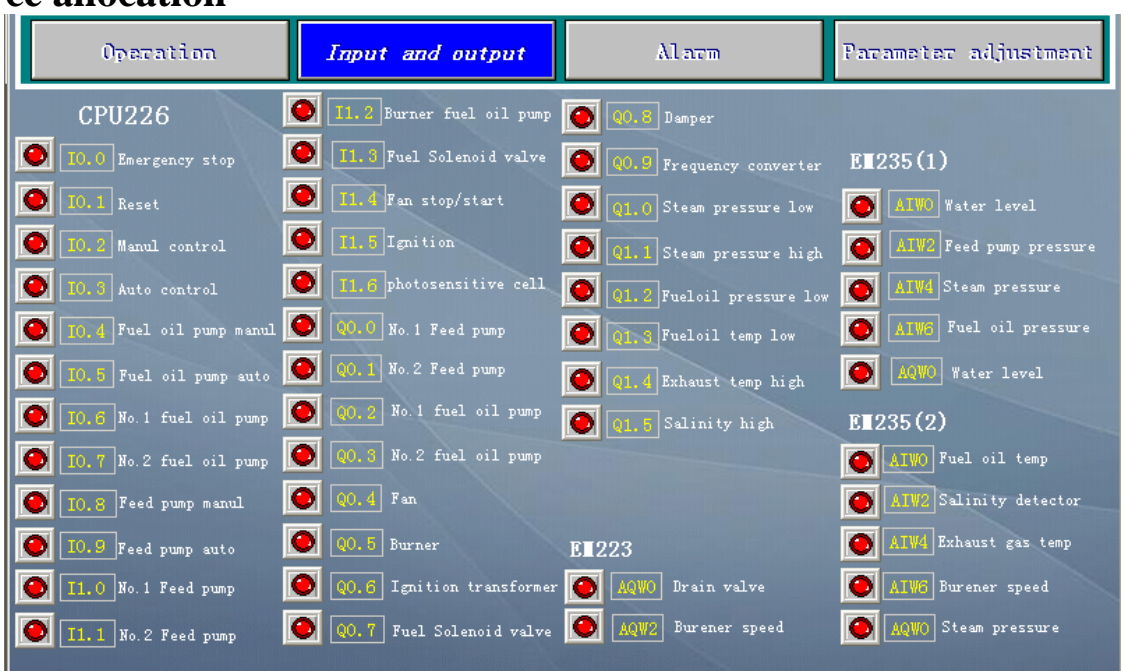

Figure 3 Automatic control system input and output interface

\section{Test result}

By PLC software test in the full digital simulation test environment, it is verified that the feed pump's and fuel pump's automatic start-stop and switching process are correct.

Through the hardware in the loop test technology, test the effectiveness of the boiler alarm point.After the alarm, the boiler is protected according to the procedure, the system failure rate is low, the number of failures in the whole life period is small, and the reliability is high, The system meets the requirements of testing and verifying the performance of the equipment under fault conditions.

Connecting hardware. According to the operation process, either manual or automatic mode control, the boiler combustion can be normal, the control system runs normally, sound and light alarm is working properly. Adjusting the boiler load, manually or automatically adjusting the size of the fire can meet the requirements of load changes.

\section{Conclusion}

After 2 years of application, the design of the system is stable, highly reliable and has low failure rate, which can meet the requirements of design and ship.The alarm panel of the touch screen panel can clearly display the alarm point, which is convenient for the crew to find the fault point and quickly eliminate the fault.According to the control system of the real ship boiler, different modules can be matched with each other, and the design has the advantages of high penetration, high compatibility and good popularization prospect. In the future, we will further optimize the boiler energy saving and air pollution prevention.

\section{References}

[1] Adam Milik. On Hardware Synthesis and Implementation of PLC Programs in FPGAs [J]. Microprocessors and Microsystems.2016

[2] Feiping Zhang "Design of boiler real time monitoring system based on PLC control”, Technology Outlook . 2017.

[3] Jianhai Li,Chenggang Wang. "Design of strain monitoring system based on PLC and touch screen”, Journal of Ordnance Engineering . 2017 